\title{
Molecular Association Studies on Polyvinyl Alcohol at Different Concentrations
}

\author{
Richa Saxena $\mathbb{D I}^{1,2}$ and S. C. Bhatt ${ }^{1}$ \\ ${ }^{1}$ Ultrasonic and Dielectric Laboratory, Department of Physics, H.N.B. Garhwal University, Srinagar, Uttarakhand, India \\ ${ }^{2}$ IFTM University, Lodhipur Rajput, Delhi Road, Moradabad 244001, India
}

Correspondence should be addressed to Richa Saxena; saxena.richa23@gmail.com

Received 17 August 2017; Revised 30 October 2017; Accepted 6 November 2017; Published 17 January 2018

Academic Editor: Antonio Facchetti

Copyright (C) 2018 Richa Saxena and S. C. Bhatt. This is an open access article distributed under the Creative Commons Attribution License, which permits unrestricted use, distribution, and reproduction in any medium, provided the original work is properly cited.

\begin{abstract}
Ultrasonic velocities, densities, and viscosities have been measured for the solution of polyvinyl alcohol in water at concentration range of $0.3 \%$ to $1 \%$ at temperature $35^{\circ} \mathrm{C}$. Ultrasonic velocities have been measured using variable path ultrasonic interferometer at $1 \mathrm{MHz}$ frequency. The acoustical parameters like adiabatic compressibility, acoustic impedance, intermolecular free length, and relaxation time have been calculated by using above-mentioned values of ultrasonic velocities, densities, and viscosities. The variation of these acoustical parameters is explained in terms of solute-solvent interaction in a polymer solution.
\end{abstract}

\section{Introduction}

For many years ultrasound has been used in a variety of fields such as biology, biochemistry, dentistry, engineering, geology, industry, medicine, and polymers [1]. The study of molecular interaction in binary and ternary liquid mixtures plays an important role in molecular sciences. In recent years ultrasound has become a powerful tool in providing information about the physiochemical properties of liquid system [2-5]. The study of molecular interactions in the polymer and solvent throws light on the processes involving polymer production and their uses. The deviation of ultrasonic sound velocity and several other thermodynamic properties of electrolytic solutions and binary and ternary mixtures with various concentrations has been investigated by various researchers [6-8].

The ion-dipole interaction depends mainly on ion size and polarity of the solvent. The strength of ion-dipole attraction is directly proportional to size of the ion, charge, and the magnitude of the dipole, but inversely proportional to the distance between the ions and the dipolar molecules [9-13] of polymer solutions and has shown that ultrasonic velocity and its allied parameters provide more information on molecular interactions which are of the utmost importance for process involving polymer production and their uses [14]. In the present paper an attempt has been made to calculate adiabatic compressibility, acoustic impedance, intermolecular free length, and relaxation time by using measured values of ultrasonic velocities, densities, and viscosities at concentration range of $1.0 \%, 0.8 \%, 0.6 \%, 0.5 \%, 0.4 \%$, and $0.3 \%$ at $35^{\circ} \mathrm{C}$ temperature.

\section{Experimental Details}

In the present investigation polyvinyl alcohol in solid form of molecular weight approximately $(140,000 \mathrm{Da})$ is used. The solutions were prepared by adding known volume of polyvinyl alcohol to fixed volume of water and stirring under reflex, until a clear solution was obtained. The concentration range studied in the solution is $1.0 \%, 0.8 \%, 0.6 \%$, $0.5 \%, 0.4 \%$, and $0.3 \%(\mathrm{~m} / \mathrm{v})$. Different acoustical parameters like intermolecular free length and relaxation time were calculated at different concentration like $1.0 \%, 0.8 \%, 0.6 \%$, $0.5 \%, 0.4 \%$, and $0.3 \%$ and at $35^{\circ} \mathrm{C}$ temperatures at $1 \mathrm{MHz}$ frequency by using variable path ultrasonic interferometer with reproducibility of $\pm 0.4 \mathrm{~m} / \mathrm{s}$ at $35^{\circ} \mathrm{C}$. The temperature of the solution has been kept constant by circulating water from the thermostatically controlled $\left( \pm 0.1^{\circ} \mathrm{C}\right)$ water bath. The densities at different temperature were measured using $10 \mathrm{ml}$ specific gravity bottle and single pan macrobalance. The 
TABLE 1: Density $\left(\times 10^{3} \mathrm{~kg} / \mathrm{m}^{3}\right)$ of polyvinyl alcohol (PVA) at $35^{\circ} \mathrm{C}$ temperature and concentration at $1 \mathrm{MHz}$ frequency.

\begin{tabular}{lc}
\hline Concentration $(\mathrm{m} / \mathrm{v})$ & Density $\left(\right.$ at $\left.35^{\circ} \mathrm{C}\right)$ \\
\hline $1.0 \%$ & 0.996 \\
$0.8 \%$ & 0.983 \\
$0.6 \%$ & 0.978 \\
$0.5 \%$ & 0.975 \\
$0.4 \%$ & 0.973 \\
$0.3 \%$ & 0.970 \\
\hline
\end{tabular}

TABLe 2: Viscosity $\left(\times 10^{-1} \mathrm{~Pa} \cdot \mathrm{s}\right)$ of polyvinyl alcohol (PVA) at $35^{\circ} \mathrm{C}$ temperature and concentration at $1 \mathrm{MHz}$ frequency.

\begin{tabular}{lc}
\hline $\begin{array}{l}\text { Concentration } \\
(\mathrm{m} / \mathrm{v})\end{array}$ & Viscosity at $35^{\circ} \mathrm{C}$ \\
\hline $1.0 \%$ & 0.089 \\
$0.8 \%$ & 0.086 \\
$0.6 \%$ & 0.077 \\
$0.5 \%$ & 0.074 \\
$0.4 \%$ & 0.073 \\
$0.3 \%$ & 0.072 \\
\hline
\end{tabular}

TABLE 3: Ultrasonic velocity (m/s) of polyvinyl alcohol (PVA) at different concentration at $1 \mathrm{MHz}$ frequency.

\begin{tabular}{lc}
\hline $\begin{array}{l}\text { Concentration } \\
(\mathrm{m} / \mathrm{v})\end{array}$ & $\begin{array}{c}\text { Ultrasonic velocity at } \\
35^{\circ} \mathrm{C}\end{array}$ \\
\hline $1.0 \%$ & 1509.9 \\
$0.8 \%$ & 1503.2 \\
$0.6 \%$ & 1501.3 \\
$0.5 \%$ & 1495.9 \\
$0.4 \%$ & 1483.8 \\
$0.3 \%$ & 1482.5 \\
\hline
\end{tabular}

uncertainty in density measurements was found to be about $0.5 \mathrm{~kg} / \mathrm{m}^{3}$. The viscosity of the mixtures was determined by using Ostwald's viscometer, which was kept inside a doublewalled jacket, in which water from thermostat water bath was circulated. The inner cylinder of this double-wall-glass jacket was filled with water of desired temperature so as to establish and maintain the thermal equilibrium. The accuracy in the viscosity measurements is within $\pm 0.5 \%$. These parameters are calculated by using standard relations [15-17].

\section{Result and Discussion}

In the present work density, viscosity, and ultrasonic velocity have been measured at different concentration of polyvinyl alcohol, at $35^{\circ} \mathrm{C}$ which is shown in Tables 1, 2, and 3, respectively. By using these values for PVA, adiabatic compressibility, acoustic impedance, intermolecular free length, relaxation time, and ultrasonic attenuation have been calculated by using well known relations [18-20] and the results have been presented in Tables 4, 5, 6, 7, and 8, respectively.
TABle 4: Adiabatic compressibility $\left(\times 10^{-10} \mathrm{~kg}^{-1} \mathrm{~ms}^{2}\right)$ at different concentration at $1 \mathrm{MHz}$ for polyvinyl alcohol (PVA).

\begin{tabular}{lc}
\hline $\begin{array}{l}\text { Concentration } \\
(\mathrm{m} / \mathrm{v})\end{array}$ & $\begin{array}{c}\text { Adiabatic compressibility } \\
\text { At } 35^{\circ} \mathrm{C}\end{array}$ \\
\hline $1.0 \%$ & 4.404 \\
$0.8 \%$ & 4.502 \\
$0.6 \%$ & 4.537 \\
$0.5 \%$ & 4.583 \\
$0.4 \%$ & 4.668 \\
$0.3 \%$ & 4.691 \\
\hline
\end{tabular}

TABle 5: Acoustic impedance $\left(\times 10^{3} \mathrm{~kg} \mathrm{~m}^{2} \mathrm{~s}^{-1}\right)$ at different concentration at $1 \mathrm{MHz}$ for polyvinyl alcohol (PVA).

\begin{tabular}{lc}
\hline $\begin{array}{l}\text { Concentration } \\
(\mathrm{m} / \mathrm{v})\end{array}$ & Acoustic impedance at $35^{\circ} \mathrm{C}$ \\
\hline $1.0 \%$ & 1503.9 \\
$0.8 \%$ & 1477.6 \\
$0.6 \%$ & 1468.3 \\
$0.5 \%$ & 1458.5 \\
$0.4 \%$ & 1443.7 \\
$0.3 \%$ & 1438 \\
\hline
\end{tabular}

TABLE 6: Intermolecular free length $\left(\times 10^{-13} \mathrm{~m}\right)$ at different concentration at $1 \mathrm{MHz}$ for polyvinyl alcohol (PVA).

\begin{tabular}{lc}
\hline $\begin{array}{l}\text { Concentration } \\
(\mathrm{m} / \mathrm{v})\end{array}$ & $\begin{array}{c}\text { Intermolecular free length } \\
\text { at } 35^{\circ} \mathrm{C}\end{array}$ \\
\hline $1.0 \%$ & 2.84 \\
$0.8 \%$ & 2.872 \\
$0.6 \%$ & 2.883 \\
$0.5 \%$ & 2.898 \\
$0.4 \%$ & 2.924 \\
$0.3 \%$ & 2.931 \\
\hline
\end{tabular}

TABLE 7: Relaxation time $\left(\times 10^{-12} \mathrm{~s}\right)$ at different concentration at $1 \mathrm{MHz}$ for polyvinyl alcohol (PVA).

\begin{tabular}{lc}
\hline $\begin{array}{l}\text { Concentration } \\
(\mathrm{m} / \mathrm{v})\end{array}$ & $\begin{array}{c}\text { Relaxation time at } \\
35^{\circ} \mathrm{C}\end{array}$ \\
\hline $1.0 \%$ & 5.23 \\
$0.8 \%$ & 5.16 \\
$0.6 \%$ & 4.66 \\
$0.5 \%$ & 4.61 \\
$0.4 \%$ & 4.54 \\
$0.3 \%$ & 4.5 \\
\hline
\end{tabular}

The variations of these parameters with temperature and concentration have been shown in Figures 1-8, respectively.

Polyvinyl alcohol in solid form of molecular weight approximately 140,000 is taken. Solution were prepared by adding known weight of polyvinyl alcohol of molecular weight approximately 140,000 to fixed volume of water and 


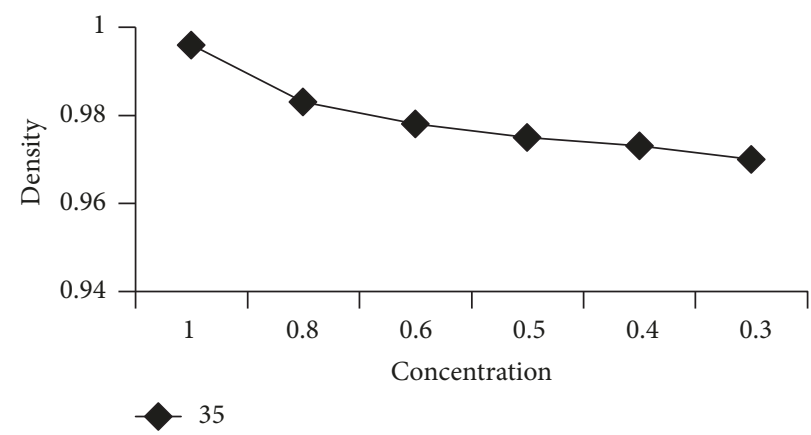

Figure 1: Variation of density with concentration at $35^{\circ} \mathrm{C}$ temperature.

TABLE 8: Ultrasonic absorption $\left(\times 10^{-15} \mathrm{~s}^{2} \mathrm{~m}^{-1}\right)$ at different concentration at $1 \mathrm{MHz}$ for polyvinyl alcohol (PVA).

\begin{tabular}{lc}
\hline $\begin{array}{l}\text { Concentration } \\
(\mathrm{m} / \mathrm{v})\end{array}$ & $\begin{array}{c}\text { Ultrasonic absorption at } \\
35^{\circ} \mathrm{C}\end{array}$ \\
\hline $1.0 \%$ & 6.84 \\
$0.8 \%$ & 6.79 \\
$0.6 \%$ & 6.13 \\
$0.5 \%$ & 6.21 \\
$0.4 \%$ & 6.05 \\
$0.3 \%$ & 6.00 \\
\hline
\end{tabular}

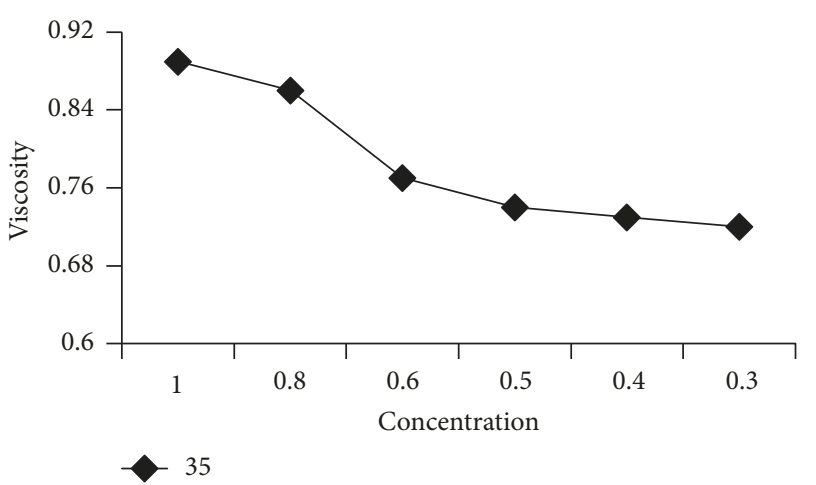

FIGURE 2: Variation of viscosity with concentration at $35^{\circ} \mathrm{C}$ temperature.

stirring under reflex, until a clear solution was obtained. Figure 1 represents the variation of density with concentration at $35^{\circ} \mathrm{C}$. Density increases with increase in concentration. These are in agreement with earlier workers [21]. It may be due to electro striction in that solution. This electrostriction decreases the volume and hence increases the density as a number of solute molecules increase the electrostriction and density. It is evident from Figure 2 that viscosity increases with increase in concentration of PVA. This is showing similar trend as reported by earlier workers [22]. The variations of ultrasonic velocity with concentration have been shown in Figure 3. Ultrasonic velocity increases with increase in concentration of PVA. The increase in ultrasonic velocity with concentration indicates increase in cohesion forces due too powerful-solvent interactions. The results

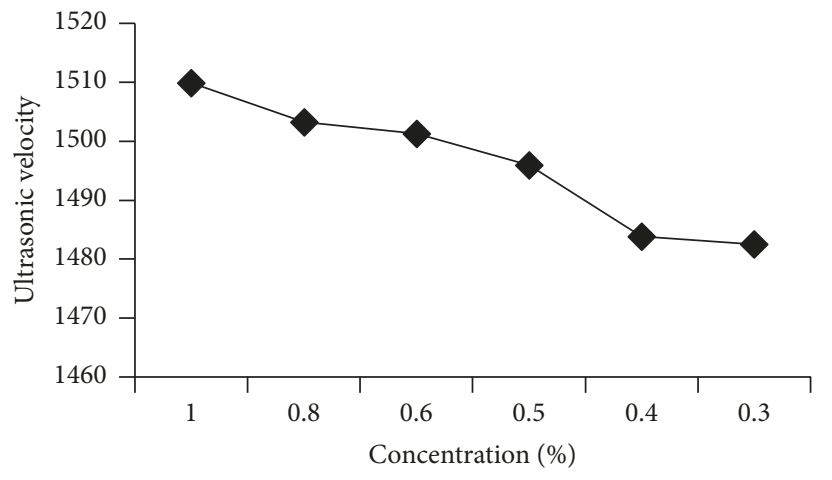

35

FIGURE 3: Variation of ultrasonic velocity with concentration at v35 $\mathrm{C}$ temperature.

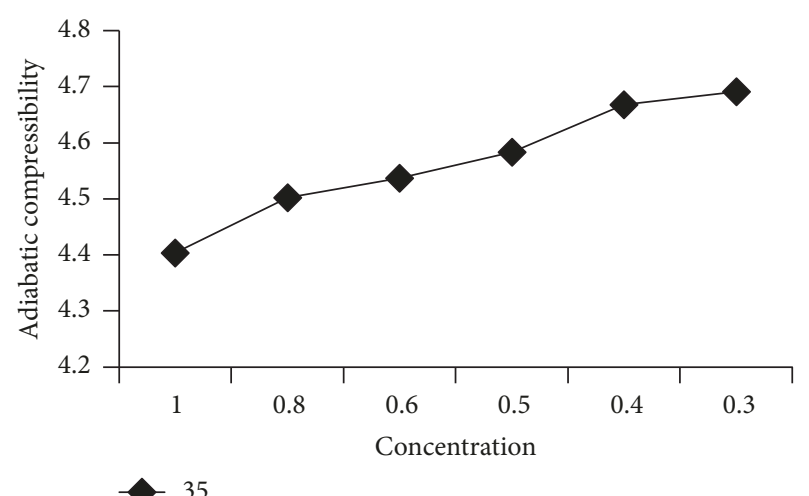

FIGURE 4: Variation of adiabatic compressibility with concentration at $35^{\circ} \mathrm{C}$ temperature.

are in good agreement with earlier worker. Variation of adiabatic compressibility with concentration is shown in Figure 4. It is evident that adiabatic compressibility decreases with increase in concentration of polyvinyl alcohol in solution. This decrease in adiabatic compressibility indicates the enhancement of the bond strength at this concentration. Figure 5 depicts the variation of acoustic impedance with concentration. It is seen that it increases with increase in concentration of polyvinyl alcohol in the solution. This is in agreement with the requirement as both ultrasonic velocity 


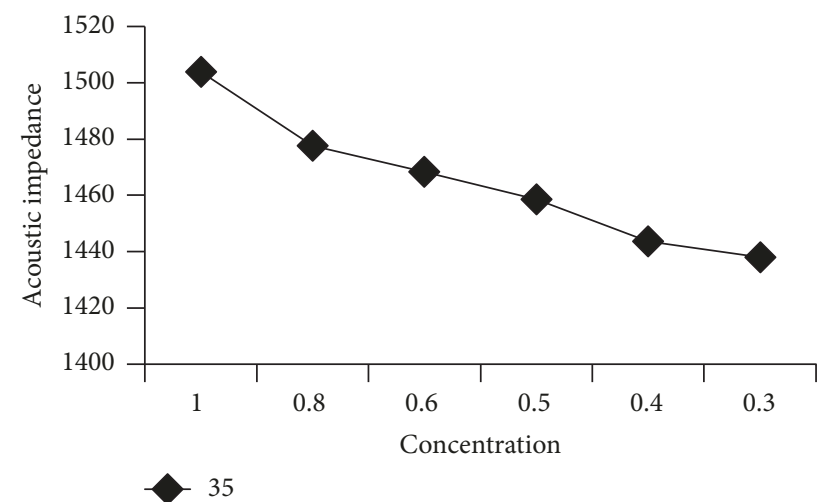

FIGURE 5: Variation of acoustic impedance with concentration at $35^{\circ} \mathrm{C}$ temperature.

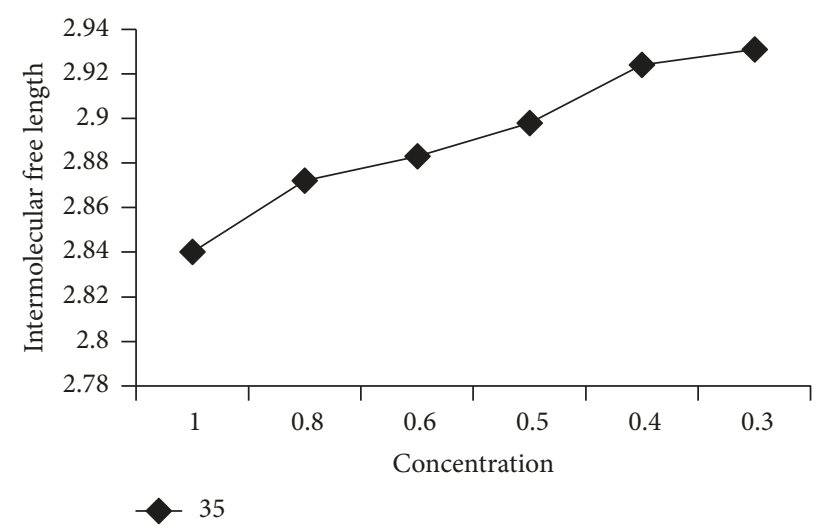

FIGURE 6: Variation of intermolecular free length with concentration at $35^{\circ} \mathrm{C}$ temperature.

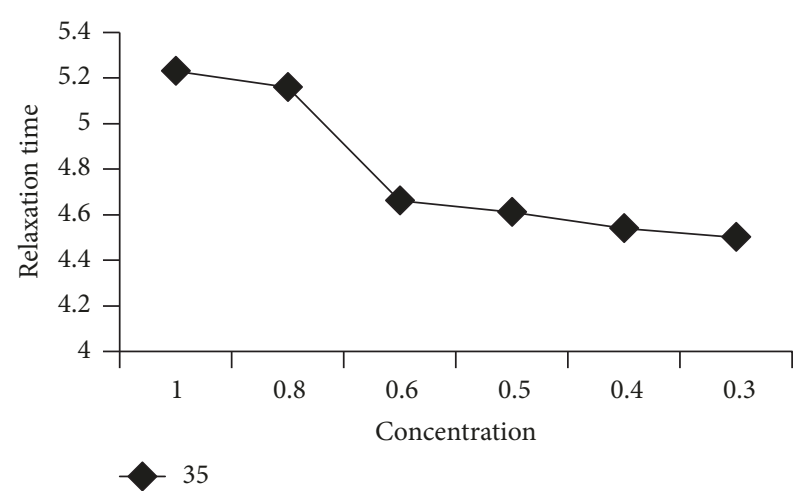

FIGURE 7: Variation of relaxation time with concentration at $35^{\circ} \mathrm{C}$ temperature.

and density increase with increase in concentration of the solute and also effective due to solute-solvent interactions. Variation of intermolecular free length with concentration is presented in Figure 6 which shows that it decreases with increase in concentration of PVA in solution. Similar results are obtained by earlier researchers. It is evident from Figure 7 that relaxation time increases with increase in concentration of polyvinyl alcohol in solution. Variation of ultrasonic

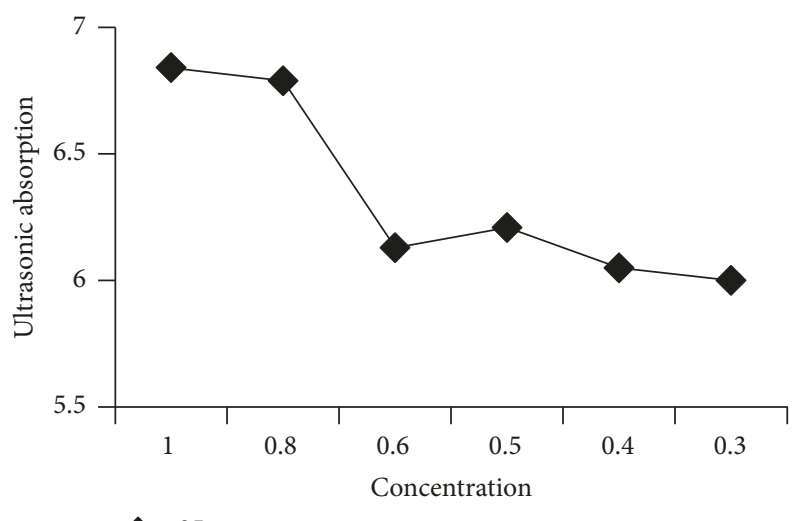

FIGURE 8: Variation of ultrasonic absorption with concentration at $35^{\circ} \mathrm{C}$ temperature.

absorption with concentration is shown in Figure 8. It is observed that ultrasonic absorption increases with increase in concentration of PVA in the solution. Increase in the value of relaxation time and ultrasonic absorption with concentration can be explained in terms of the motion of the molecular interaction forces.

\section{Conflicts of Interest}

The authors declare that they have no conflicts of interest.

\section{References}

[1] T. J. Mason, Ed., Sonochemistry: The Uses of Ultrasound in Chemistry, Royal Society of Chemistry, 1990.

[2] A. K. Dash and R. Paikaray, "Acoustical study in binary liquid mixture containing dimethyl acetamide using ultrasonic and viscosity probes," Der. Chem. Sinica, vol. 5, pp. 81-88, 2014.

[3] R. Palani, S. Saravanan, and R. Kumar, "Ultrasonic studies on some ternary organic liquid mixtures at 303, 308 and 313k," RASĀYAN Journal of Chemistry, vol. 2, no. 3, pp. 622-629, 2009.

[4] T. S. Antony, M. P. John Peter, and J. Y. Raj, "Phytochemical Analysis of Stylosanthes fruticosa using UV-VIS, FTIR and GCMS," Research Journal of Chemical Sciences, vol. 3, no. 11, pp. 1423, 2013.

[5] A. A. Mistry, V. D. bhandakkar, and O. P. Chimankar, J. of Chem and Pharma Res, vol. 4, no. 1, pp. 170-174, 2012.

[6] S. Oswal and A. T. Patel, "Speeds of sound, isentropic compressibilities, and excess volumes of binary mixtures. 2. Mono-nalkylamines with cyclohexane and benzene," Journal of Chemical \& Engineering Data, vol. 40, no. 1, pp. 194-198, 1995.

[7] A. Awasthi and J. P. Shukla, "Ultrasonic and IR study of intermolecular association through hydrogen bonding in ternary liquid mixtures," Ultrasonics, vol. 41, no. 6, pp. 477-486, 2003.

[8] Y. V. Patel and P. H. Parsania, "Ultrasonic velocity study of poly(R,R I,4,4'-cyclohexylidene diphenylene diphenyl ether4,4I-disulfonate) solutions at 30, 35 and $40 \circ \mathrm{C}$," European Polymer Journal, vol. 38, no. 10, pp. 1971-1977, 2002.

[9] S. Kalyana Sundaram and B. Sundaram, Journal of Acoustical Society of India, vol. 27, p. 375, 1999. 
[10] S. Kalyana Sundaram and B. Sundaram, Journal of Acoustical Society of India, vol. 27, p. 363, 1999.

[11] B. Sundaresan and A. Srinivasa Rao, "Molecular interaction studies on poly(vinyl chloride) in chlorobenzene by acoustic method," Polymer Journal, vol. 26, no. 11, pp. 1286-1290, 1994.

[12] S. Kalyanasundaram, A. Manuel Stephen, and A. Gopalan, "Ultrasonic studies of poly (methyl acrylate) in dimethyl formamide," J Polym. Matt, vol. 12, p. 177, 1995.

[13] T. H. Polym, “Solution Butterworth, Scientific," London, 1956.

[14] I. Johnson, M. Kalidoss, and R. Srinivasamoorthy, Journal of Pure Applied Ultrasonics, vol. 25, p. 136, 2003.

[15] R. Saxena and S. C. Bhatt, "Molecular Interactions in Binary Mixture of Polymethylmethacrylate with Acetic Acid," International Journal of Chemistry, vol. 2, no. 2, 2010.

[16] S. Bhatt C, V. Lingwal, K. Singh, and B. Semwal S, "Acoustical parameters of some molecular liquids," Journal of the Acoustical Society of India, vol. 28, pp. 293-296, 2000.

[17] S. Ravichandran and K. Ramanathan, "Ultrasonic investigations of MnSO4, NiSO4 and CuSO4 aqueous in polyvinyl alcohol solution at 303K," RASĀYAN Journal of Chemistry, vol. 3, no. 2, pp. 375-384, 2010.

[18] A. R. Shah and P. H. Parsania, "Ultrasonic Velocity Studies on Poly(4,4/-Cyclohexylidene-2,2/-Dimethyldiphenylene/ Diphenylene-3, 3/-Benzophenone Disulfonates) in Chlorinated and Aprotic Solvents," Journal of Polymer Materials, vol. 14, no. 1, pp. 33-41, 1997.

[19] J. Desai A and P. H Parsania, "Ultrasonic studies of poly(1, 1-cyclohexlidonyl-4, 4 diphenylene2, 4-toulene) disulfonate at 300 C," Journal of Pure Applied Ultrasonic, vol. 19, pp. 65-69, 1997.

[20] V. Kagathara, M. Sanariya, and P. Parsania, "Sound velocity and molecular interaction studies on chloro epoxy resins solutions at 30॰C," European Polymer Journal, vol. 36, no. 11, pp. 23712374, 2000.

[21] J. Vidyanand, "Quality circle implementation in India organization: an alternative," DECISION, vol. 24, pp. 1-4, 1997.

[22] M. Umadevi, R. Kesavasamy, V. Ponnusamy, N. S. Priya, and K. Ratina, "Intermolecular interactions in ternary liquid mixtures by ultrasonic measurements," Indian Journal of Pure \& Applied Physics, vol. 53, no. 12, pp. 796-803, 2015. 


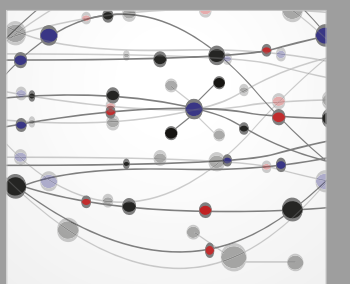

The Scientific World Journal
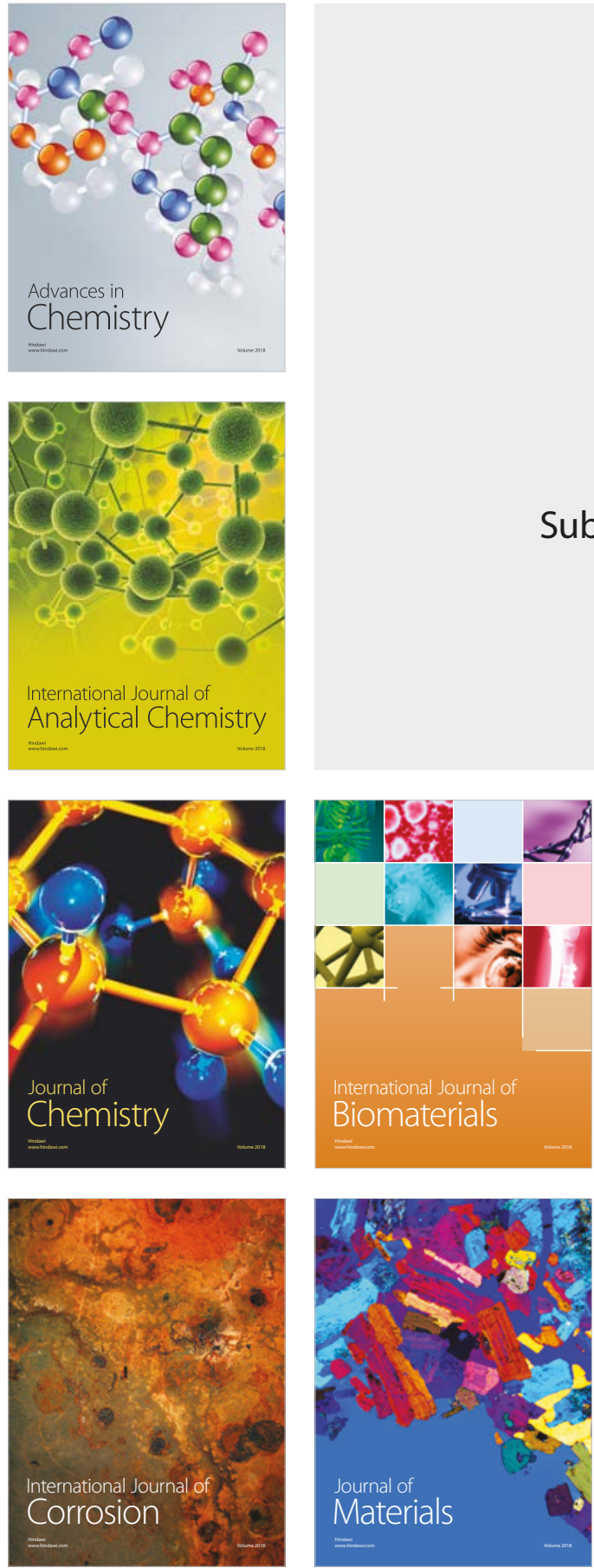

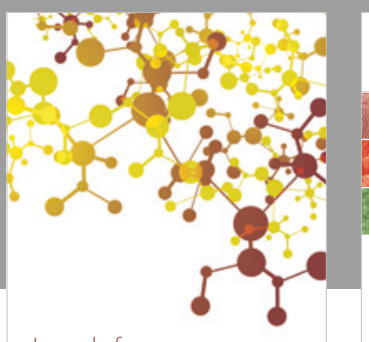

Journal of

Applied Chemistry
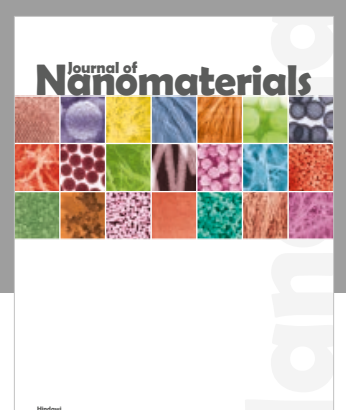

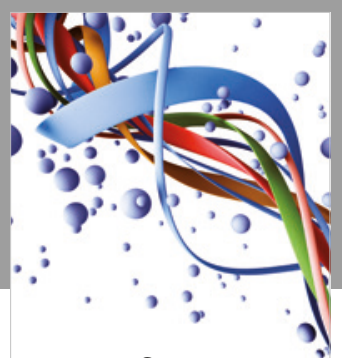

Scientifica

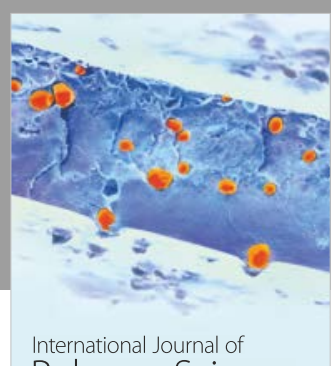

Polymer Science

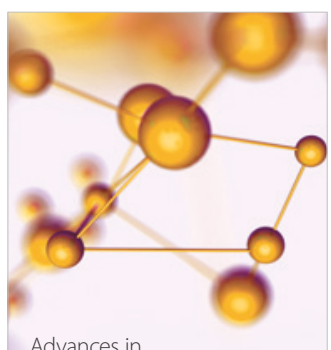

Physical Chemistry
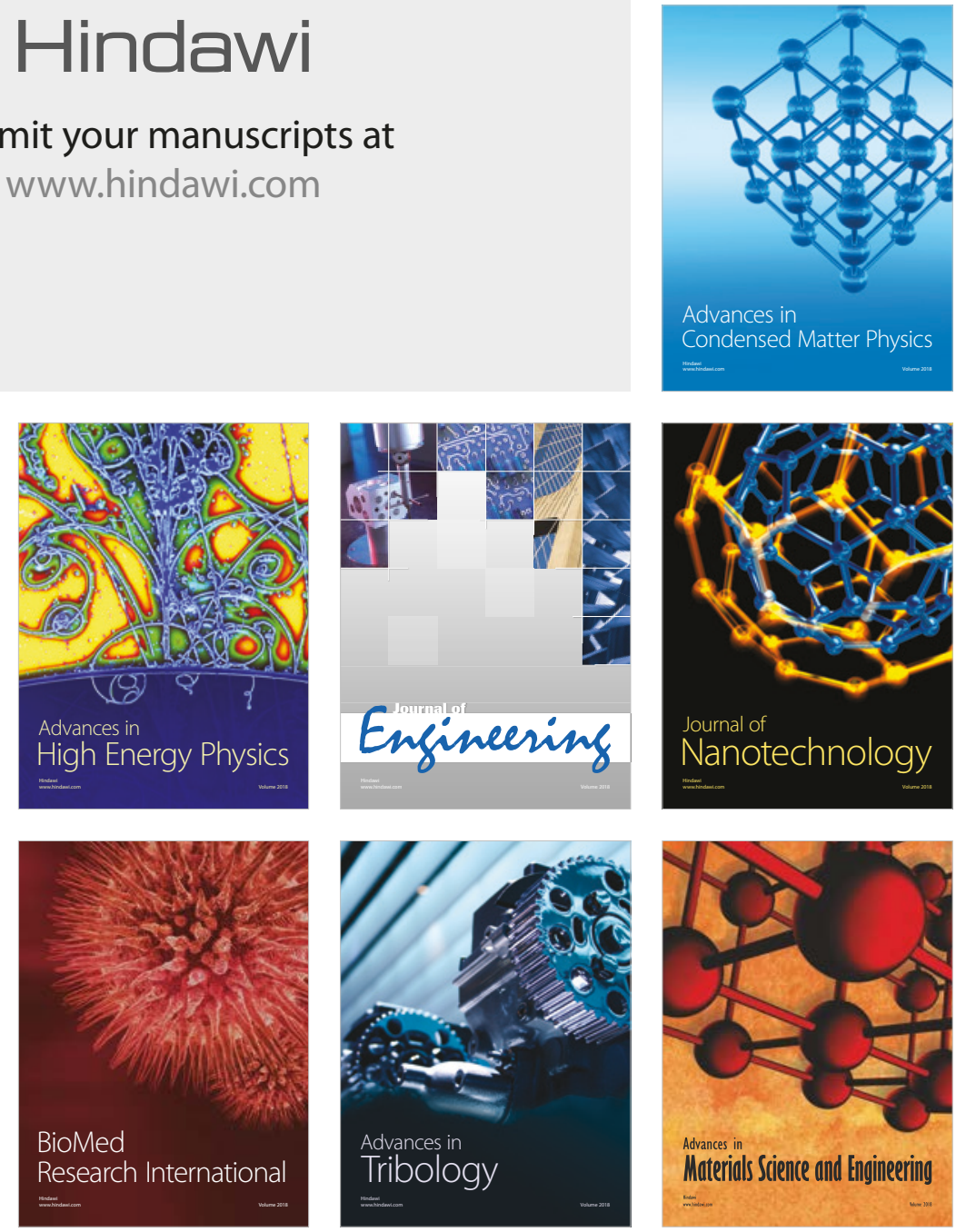